\title{
Organization and Operation Mechanism of Urban Design Guidance of Metro Hub Areas
}

\author{
Liang Wu, Wei Lu, Zongchao Gu \\ School of Architecture and Fine Art, Dalian University of Technology, Dalian, China \\ Email: wuliang1026@126.com
}

How to cite this paper: $\mathrm{Wu}, \mathrm{L}$., $\mathrm{Lu}, \mathrm{W}$. and $\mathrm{Gu}$, Z.C. (2018) Organization and Operation Mechanism of Urban Design Guidance of Metro Hub Areas. Open Journal of Social Sciences, 6, 1-9.

https://doi.org/10.4236/jss.2018.610001

Received: September 11, 2018

Accepted: October 7, 2018

Published: October 10, 2018

Copyright ( $) 2018$ by authors and Scientific Research Publishing Inc. This work is licensed under the Creative Commons Attribution International License (CC BY 4.0).

http://creativecommons.org/licenses/by/4.0/

\section{cc) (i) Open Access}

\begin{abstract}
Urban spatial relationship of Metro Hub Area is extremely complex, and urban design guidance plays an important role in promoting the development of urban space. Firstly, urban design institution system should be established with both restraint and incentive, making it be integrated with the planning system and obtain legal status. Secondly, the special agency unit with special committees in charge of urban design should be established in the urban planning management department to strengthen the coordination between the relevant agencies. Finally, whole process multipartite mode should be established, maintaining communication and supervision at all stages of urban development, and promoting the smooth implementation of urban design.
\end{abstract}

\section{Keywords}

Urban Design Guidance, Metro Hub Area, Institution System, Multipartite

\section{The Significance of Urban Design Guidance of Metro Hub Areas}

Guidance contains the meaning of advice and control, which is a kind of management behavior with a clear purpose. Urban design guidance refers to a series of administrative activities taken by government departments involved in planning compilation, planning examination and approval, planning permission and the whole process of planning implementation in order to better exert the restraint and guidance role of urban design on the future built environment and achieve the goal of urban design. Urban design guidance mechanism is an important guarantee for the construction of efficient, orderly and suitable urban space of Metro Hub Areas.

Chen Jikai put forward the "small-scale principle" in the coordination concept 
of "adaptive urban design", that is, "to analyze the special urban problems and specific use objects (service class and individuals) in the urban life for specific urban areas, to avoid discussing urban problems and dealing with urban relations in a large and empty way" [1]. Undoubtedly, the Metro Hub Area is one of those with the most complex spatial relationships in the city, and it is also a window area for the display of urban characteristics and images. It has been designated as "key urban design area" in many cities all over the world, such as Singapore, Hong Kong, Nanjing and so on. The complexity of station-area urban space in spatial relationship and development process makes its urban design guidance valuable.

First of all, whether it is macro structural strategy or micro quality strategy, the goal of urban design of the station-area is station-city coordinated development. It is an overall consideration of urban space and even social relations. The interests involved are various including the government, public, land owners and developers, and the contradictions and resistance are also various. Through certain administrative means, constraining and balancing the relationship between the parties from the overall and long-term perspective is the key step to implement the urban design strategies.

Secondly, the adaptive development of urban space of metro hub areas needs a long process, especially when the station-area space is in the overall transition stage, the urban environment is always changing, which requires that the initial urban design objectives must be consistent and unified in the long-term dynamic development. At the same time, the details of the implementation of the urban design strategies should be adjusted in a timely manner, and the rules should not be adhered to. These two aspects of the requirements are no longer only the problems of technical methods of urban design, but more problems of management and operation, which if not relying on sound urban design guidance mechanism will be difficult to achieve.

\section{Institutional Guarantee: Constraints and Incentives}

The organization and operation of urban design is generally subordinate to the urban planning compilation system and the urban planning administration department is specifically responsible for it. Whether in the overall planning or detailed planning stage, urban design guidance is generally required to become one of the important contents, that is, urban design should be integrated with the urban planning system, not only the overall urban design, but also the detailed urban design. The conception of urban design in the previous stage should be embodied in the planning of the next stage with more microscopic and specific control requirements. However, in the actual organization and operation, there is still a big gap in the degree of attention and standardization of urban design work between different countries. This gap is first reflected in the institution and management level.

The Metro Hub Area studied in this paper is generally at the level of "basic 
unit" (or similar to it) of Regulatory Detailed Planning, but compared with other "basic units", the complex and three-dimensional characteristics of urban space in Metro Hub Area make it impossible to guide and control the development of urban space in the station area effectively by simple planning. The detailed urban design of three-dimensional space plays a special and important role. The results of urban design should be reflected in the content of planning so as to obtain a legal status. Moreover, the depth of urban design of Metro Hub Area can not only stay on the general level of building volume, combination, color, and so on, as other areas do. The guidance of key elements such as pedestrian system and public space should become its core content.

Therefore, some key areas including Metro Hub Area firstly should be divided into "special units" of the Regulatory Detailed Planning compilation in the institution construction through local laws and regulations of each city, and require the compilation results to include the corresponding urban design guidelines. Secondly, the restrictive or guiding detailed requirements of urban space from whole to part should be put forward in the urban design guideline of station-area, and even compiling the guidance rules of pedestrian system and public space separately should be considered. Whether in the general urban design guidelines or specific design rules of pedestrian systems or public space, the control contents in the structural level which involve the public interest should be the statutory standards and constraints of the new or transformation project implementation, and those proposed contents which are related to the interests of the development subject and have positive impact on urban space should enable commercial development to actively participate in the construction of urban space of station-area through the formulation of flexible incentive policies, such as public financial subsidies, transfer of space development rights, floor area incentives and so on. The coexistence of rigid restraint institution and flexible incentive institution is an important guarantee to realize the adaptive development of urban space in Metro Hub Areas.

Taking Singapore's urban design institution as an example, in the stage of drafting the plan, it begins to compile the three-dimensional plan, adding the contents of urban design, such as three-dimensional space, height control, pedestrian system, open space and so on. This includes not only the delimitation of urban design areas, but also the detailed urban design of key plots [2]. However, except for a few cities such as Shanghai and Nanjing, there is only rigid planning control for the Metro Hub Area, and lack of adaptable and omni-directional urban design in mainland China, let alone transforming the urban design results into statutory rules for implementation.

In recent years, Nanjing has actively explored the construction of urban design institution, and established the urban design management and control mechanism of "form control \& policy control", which has a certain demonstration significance, as shown in Figure 1. Corresponding to the stage of urban planning, the urban design of Nanjing is divided into four levels: Master Urban De- 
sign, Zone Urban Design, District Urban Design and Block Urban Design; and the key areas including Metro Hub Area are designated as "special intent areas". Being different from the general rules of common areas, the urban design of these areas is developed according to the depth of Constructive Detailed Planning, and detailed control and guidance requirements for traffic flow lines, underground space, interface types and so on are proposed, and urban design plans are formed, as shown in Figure 2. A series of urban design technical guidelines and control policies, such as Nanjing City Design Guidelines, Some provisions on further Highlighting the style of ancient capital and improving the quality of the old city and so on, are formulated, taking the urban design results as an important basis for investment, land transfer and scheme approval.

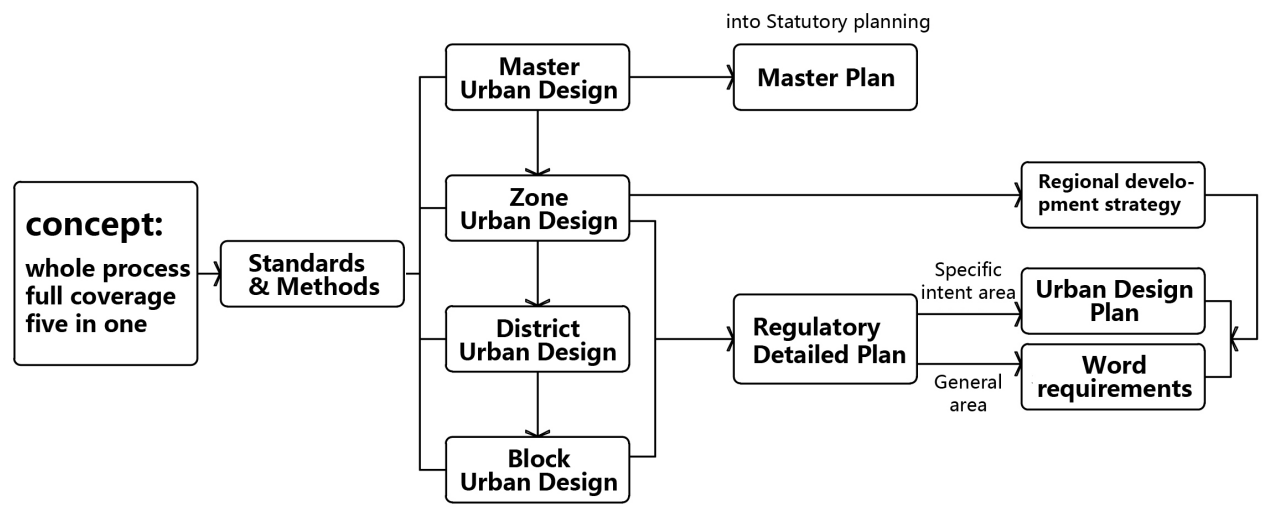

Source: WeChat: Urban Design Academic Committee, 2016.11.26.

Figure 1. Nanjing urban design system.

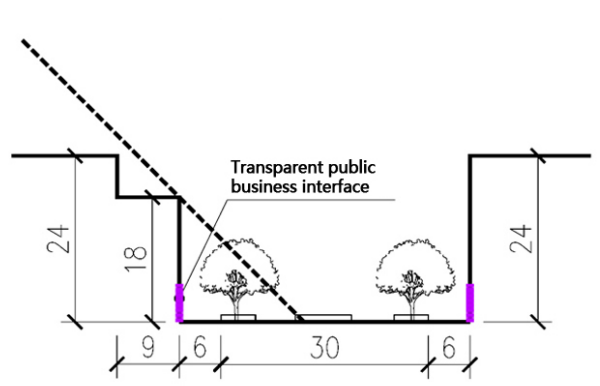

Schematic diagram of important section types
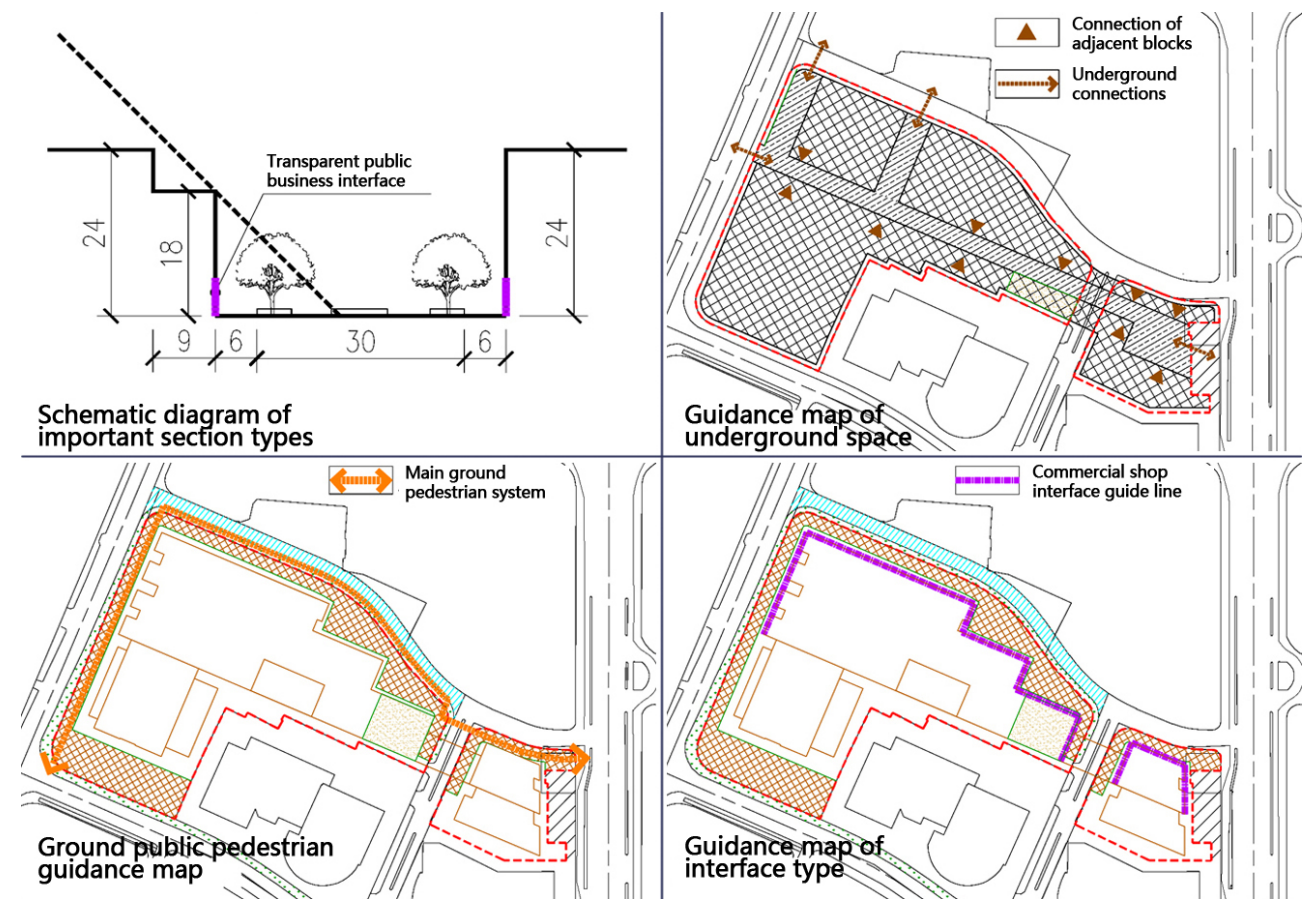

Source: http://www.njghj.gov.cn

Figure 2. Urban design guidelines of Dongtieguanxiang Block of Xinjiekou District, Nanjing. 


\section{Organization: Integrated and Coordinated Management}

All the technical measures and institutional arrangements adopted to achieve a good integration of urban design and planning systems will ultimately be implemented through the operation of various institutions [2]. The compilation, organization and management of urban design is a professional and systematic work, and is an important responsibility of the planning departments of local governments. In the specific process of organization and management, besides being closely related to the work of urban planning at various stages, it is also closely related to the planning management and development planning in the fields of transportation, municipal administration, land and construction.

Urban development and renewal in urban centers with a high concentration of public resources, especially in Metro Hub Areas, need to go through a complex and long process. In this process, the implementation of urban design guidance not only need to rely on the organization and operation of the competent agencies, but also need to establish a coordinated management among different departments and make reasonable use of resources to ensure balanced development between economic growth, quality of life and built environment. At present, the special unit responsible for urban design has not been set up in most of the urban planning and management departments in the mainland of China. In some cities the urban design work is involved in detailed planning organizations, making it a subsidiary part of the planning. With the increasing depth and importance of urban design work, the coordination management system of urban design, urban planning and other related departments needs to be further improved.

First of all, the relevant responsibilities of urban design or urban renewal should be gradually clarified in planning and land resources management agencies, and institutional units in charge of urban design or urban renewal should be set up with detailed planning or independent. Secondly, through the integration of management system and special committee model, an integrated coordination mechanism should be established between urban design and various closely related organizational units, such as planning, land use and urban development. The special committee is particularly important in the overall urban renewal for the urban renewal key areas with long duration and more interests like Metro Hub Areas.

The active role of the Singapore Urban Redevelopment Authority (URA) in the organization, management and coordination of urban design can serve as a model. URA is Singapore's government agency responsible for land use planning and protection. Its predecessor was the Urban Renewal Unit (URU) under the Housing Development Board (HDB) in 1964, which was reorganized into the Urban Renewal Department (URD) in 1966. URD officially became an independent institution under National Development Ministry in 1974. In 1989, the URD was merged with the former Planning Ministry and research-statistics group of National Development Ministry to set up the new Urban Redevelop- 
ment Authority, which was also responsible for the protection of built-up heritage. Since the development of the professional sector responsible for land sales and urban renewal in the Central Area in the 1960s, URA has become more integrated and diverse in its functions and roles, including land use planning, land sales, site management, protection, urban design and upgrading of building quality, and has become a superstructure encompassing the functions related to plan and urban design management [2].

In the URA organization, the Planning Conservation \& Urban Design Group (PCUDG) is the specific department responsible for the preparation of urban design. It consists of two modules: Physical Planning and Conservation \& urban design, and is headed by a chief planner and Deputy CEO with the Development Services Group, Development Control Group and Professional Development Group. The other Deputy CEO is responsible for the Strategic Planning Group, Information Systems \& Geospatial Group and Corporate Development Group, and the two major institutions, as well as the Land Sales \& Administration Group, are jointly led by the CEO and the Authority, as shown in Figure 3. The URA Authority is a statutory committee composed of professionals, civil servants, entrepreneurs, etc. It consists of several advisory committees, of which the Design Advisory Committee and the Design Guidelines Waiver Committee are closely related to urban design work. The unified management of planning, design and development by URA ensures that "urban design occurs within the framework of overall urban planning, or more accurately, urban planning occurs within the framework of urban design" [3].

\section{Operation Process: Multipartite in the Whole Process}

The establishment of urban spatial order in Metro Hub Area is gradually realized in the process of urban overall renewal, and the urban renewal in Metro Hub Area has linkage and sustainability. The change of local factors will produce

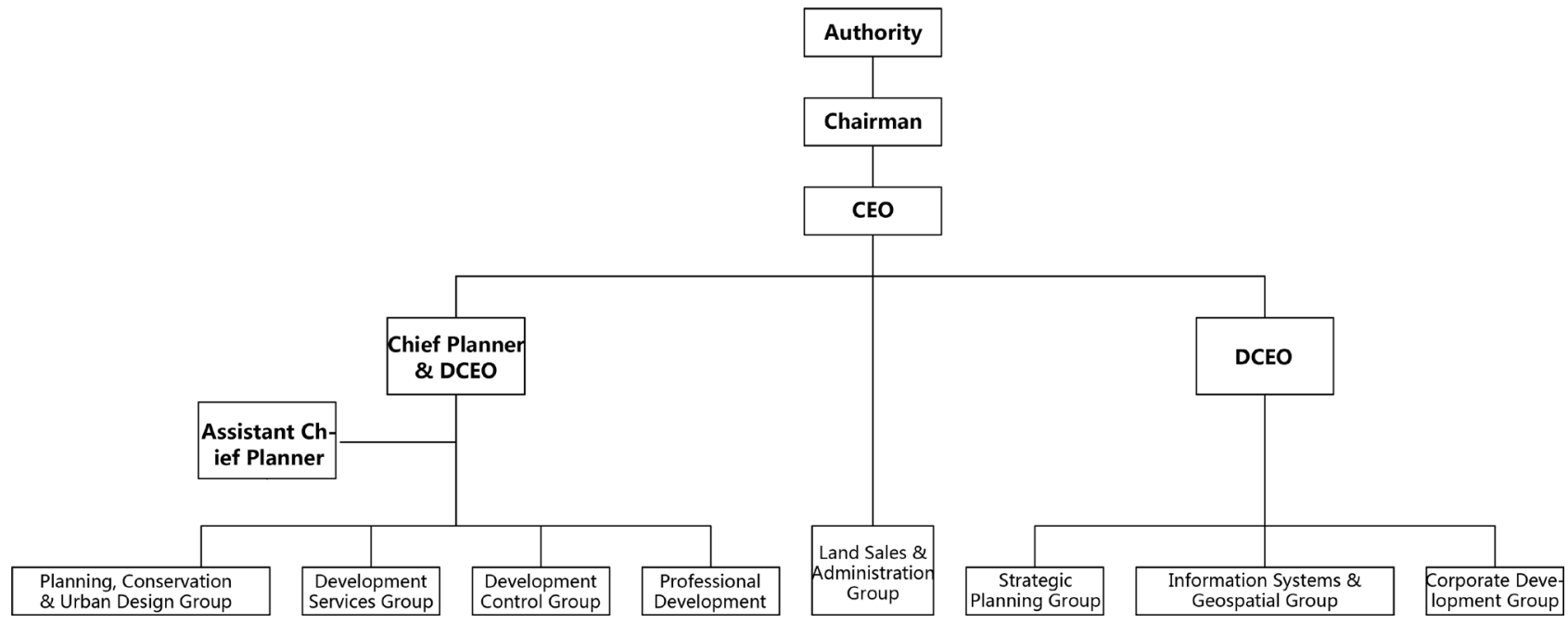

Source: http://www.ura.gov.sg

Figure 3. Organization of URA, Singapore. 
significant "space-time effect", so that urban renewal can neither be accomplished overnight nor once and for all. In order to guide the development of urban space towards the goal of organic, orderly, high-quality and high-efficiency, urban renewal should be organized, focused, phased and sustainable, forming a complete stage renewal chain of concept planning, technical preparation and construction implementation, and coordinating and balancing the needs of relevant stakeholders in each link. Feedback information should be got from the development practices, and the urban design guidance scheme should be timely adjusted to ensure the timeliness of the guidelines and strategies. Based on the above principles, besides the institutional guarantee and the operation organization's perfection, the establishment of multi-party participation mechanism in the whole process of urban design operation is also the necessary support to realize the coordinated development of stations and cities in the Metro Hub Area.

Although the construction of urban space in Metro Hub Areas is dominated by government and experts in terms of responsibilities, its users and direct interests are the broad public. Public demands are the main basis for the planning and design of urban space in Metro Hub Areas. In addition, the urban development of Metro Hub Areas, represented by commercial and rail facilities, is often large-scale, and the comprehensive development projects across blocks are common. The urban space of Metro Hub Areas can't be completely independent of these large-scale comprehensive development projects in terms of structure, function and ownership, so it also has much to do with the economic interests of developers. In this sense, the construction of urban space in Metro Hub Areas is a social behavior of game, and the government, the public and the developers participate in the game [4].

Therefore, the participants should include the representatives of all kinds of interests, such as relevant government agencies, experts in relevant fields, the public and private capital, and the form of participation should also be a real participation in the whole process of decision-making, management and implementation, giving and guaranteeing more rights of participation and initiative through the legal system. The normal communication and supervision mechanisms, such as explanation, hearing, consultation and cooperation, should be established at each stage of the formulation of the planning and design guidelines. At present, public participation consciousness and level are gradually rising in the urban planning of developing countries in Asia. However, for the urban design guidance in special areas such as Metro Hub Areas, the mechanism of participation in a wider range and more forms is still imperfect, which affects the benign development of urban space in Metro Hub Areas to a certain extent.

The multipartite mechanism has played an important role in promoting the urban design practice of Metro Hub Areas in Japan. The Shibuya area development project in Tokyo is a typical example which started more than ten years ago and is still under way. In 2005, the government designated the area around 
Shibuya Station as the "emergency regeneration area" based on the "Special Measures for Urban Regeneration Law". In the long-term renewal process, in order to coordinate the interests of the relevant parties, Review Committee of Basic Construction of Shibuya Station District, Construction Review Meeting of Shibuya Station Central Area, and Construction Adjustment Meeting of Shibuya Station Central Area composed of experts, the government, developers and track operators were established successively at different stages. Block Construction Guidelines of Shibuya Station Central District 2007, the Policy for Infrastructure Construction of Shibuya Station Block (2008), Block Construction Guidelines of Shibuya Station Central District 2010, and the Policy for Infrastructure Construction of Shibuya Station Central District (2012) have been successively formulated by means of citizen participation. Through this gradual and orderly promotion model, a series of construction and development projects including urban infrastructure like traffic plaza and land regional adjustment have been approved by urban planning and implemented in succession. "The integration of station and city development, which is promoted by coordinating official and civilian forces, is a representative example of regeneration projects in mature urban centers" [5]. The process of redevelopment and construction in the surrounding area of Shibuya Station is shown in Figure 4.

\section{Conclusions}

At present, with the rapid development of urban rail transit system in Asian high-density cities, Metro hub area is facing an important opportunity of urban spatial transformation. Urban design of Metro hub area is imperative, while urban design guidance mechanism is the institutional guarantee for the effective implementation of urban design strategy. Based on the background of urban development in Asia, this paper systematically puts forward the way to establish urban design guidance mechanism from three aspects: system, organization and operation mode, which is of great significance to promote the organic renewal and orderly development of urban space in Metro Hub Area.

Firstly, we should perfect the institution system, and establish a restraint and incentive urban design policy legally effective, which is integrated with the

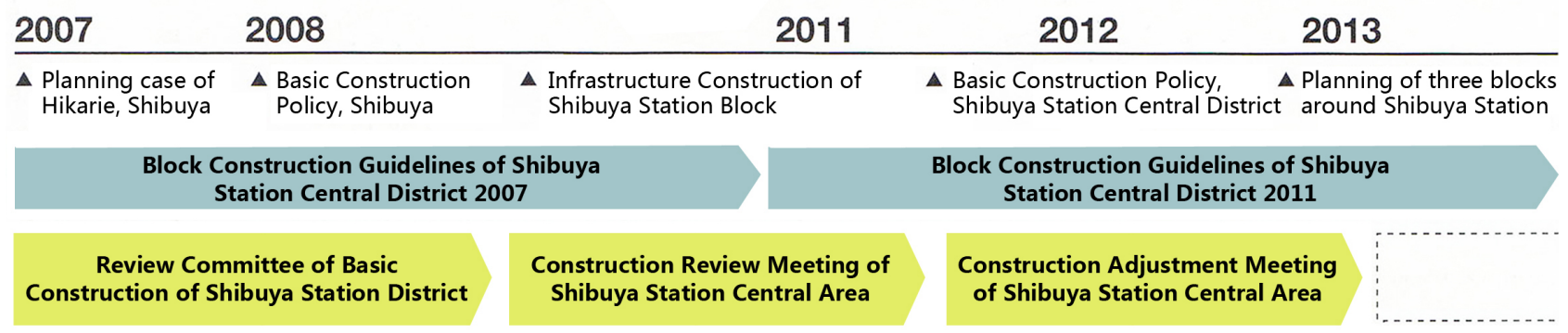

Adjustment consultations related to the construction around Shibuya Station

Source: References [5]: 134.

Figure 4. Propelling process of urban redevelopment around Shibuya Station. 
planning system, to provide clear design conditions for specific urban development projects.

Secondly, we should adjust and optimize the organization system, and set up special urban design institutions and special committees with clear responsibilities and overall management, coordinating with relevant departments.

Finally, we should improve the operation mechanism and establish a whole process multipartite operation mode, so that the problems and contradictions in urban development and construction can be solved in a timely and effective manner.

Of course, the political, cultural and economic backgrounds of different countries and regions are different to varying degrees, and the ways and modes to establish the urban design guidance mechanism are not the same. This paper puts forward some basic paradigms combined with several Asian urban cases such as Singapore, Nanjing and Tokyo, hoping to provide a reference for relevant research and practice.

\section{Conflicts of Interest}

The authors declare no conflicts of interest regarding the publication of this paper.

\section{References}

[1] Chen, J.K. (2004) Adaptive Urban Design: An Effective Theory and Application of Urban Design. China Architecture \& Building Press, Beijing.

[2] Chen, X.D. (2010) The Integration of Urban Design and Urban Planning System: Singapore Case and Suggestion. Planners, 2, 16-21.

[3] Jon, L. (2005) Urban Design: A Typology of Procedures and Products. Architectural Press, London.

[4] Deng, L.Y. (2011) Study on the Public Participation Institution of Japan. Urban Studies, 7, 62-66, 94.

[5] NIKKEN (2014) Integrated Station-City Development: The Next Advances of TOD. China Architecture \& Building Press, Beijing. 